\title{
Relação entre Desempenho Econômico-financeiro e Performance Esportiva dos principais Clubes de Futebol do Estado de São Paulo
}

\author{
Elvis Lima Batista ${ }^{1}$
}

Kleber da Silva Cajaiba

\begin{abstract}
Resumo: Esta pesquisa teve como objetivo analisar se indicadores econômico-financeiros dos principais clubes de futebol do estado de São Paulo estão atrelados aos resultados esportivos conquistados por essas agremiações. A metodologia propôs o estudo de correlação entre as variáveis independentes: Receita Bruta; Despesa com Salário; Ebit; Endividamento; e a variável dependente: ranking CBF, ao testar duas hipóteses; a H0: Não existe correlação estatística significante entre indicadores financeiros e desempenhos esportivos dos principais clubes de futebol paulistas; e, a H1: Existe correlação estatística significante entre indicadores financeiros e desempenhos esportivos dos principais clubes de futebol paulistas, por meio da ferramenta estatística 'Correlação de Spearman'. Os principais achados mostraram que, especificamente para Palmeiras e Corinthians, maiores receitas guardaram correlação com melhores resultados esportivos, da mesma maneira que menores receitas guardaram correlação com piores resultados esportivos. Todos os demais resultados não se apresentaram estatisticamente significantes, quando testados ao nível de significância de $5 \%$, ou inferiores. Assim, não se pôde afirmar que maiores despesas com salários; melhores marcadores EBIT e maior ou menor endividamento estivessem correlacionados a melhores ou piores performances esportivas dos clubes da amostra. Assim, não se pôde rejeitar a hipótese H0. Os principais clubes do estado de São Paulo, especificamente, não apresentaram comportamento isolado diverso de estudos anteriores que englobavam amostra nacional.
\end{abstract}

Palavras-chave: Clubes. Futebol. Gestão. Títulos.

\section{Correlation between Economic-Financial Performance and Sports Performance of the Main Football Clubs in the State of São Paulo} Abstract: The objective of this research was to analyze whether the economic and financial indicators of
the main soccer clubs in the state of São Paulo are linked to the sports results achieved by these
associations. The methodology proposed the study of correlation between the independent variables:
Gross Revenue; Wage Expense; Ebit; Debt and the dependent variable: CBF ranking, when testing the
hypotheses: H0: There is no significant statistical correlation between financial indicators and sports
performance of the main soccer clubs in São Paulo; and, H1: There is a significant statistical correlation
between financial indicators and sports performance of the main soccer clubs in São Paulo, through the
statistical tool Spearman's Correlation. The main findings show that specifically for Palmeiras and
Corinthians: higher revenues correlated with better sports results, just as lower revenues correlated with
worse sports results. All other results were not statistically significant, when tested at the significance level
of 5\%, or lower. Thus, it could not be stated that higher expenses with salaries, better EBIT markers and
higher or lower indebtedness were correlated to better or worse sporting performances of the clubs in the

1 Graduado em Ciências Contábeis pela Faculdade Independente do Nordeste - FAINOR. E-mail: elvisbatistacontabilidade@gmail.com

${ }^{2}$ Mestre em Ciências Contábeis pela FUCAPE Business School. Professor de Contabilidade e Estatística Aplicada da Universidade Estadual do Sudoeste da Bahia e da Faculdade Independente do Nordeste - FAINOR. E-mail: klebercajaiba@,fainor.com.br 
sample. Thus, it was not possible to reject the hypothesis H0. The main clubs in the state of São Paulo, specifically, did not treat separately from previous studies that included a national sample.

Keywords: Clubs. Soccer. Management. Titles.

\section{Introdução}

Além de ser visto como esporte e lazer, o futebol é um negócio. Seguindo a coerência de mercado os torcedores são os consumidores e o jogo, o ativo negociado. Tal tratamento do futebol brotou no momento em que a televisão começou a exibir os jogos, alcançando altíssima audiência, estimulando o interesse de patrocinadores $\mathrm{em}$ anunciarem as suas marcas ao telespectador, por intermédio das placas de publicidades nos estádios e nos uniformes dos clubes (DANTAS; BOENTE, 2011).

Nascimento (2015) afirma que um clube de futebol, assim como uma empresa de qualquer outro setor, necessita ter equilíbrio financeiro. Com isso, ela mantém-se em operação e pleiteia competitividade frente aos seus concorrentes (ESPITIA; GARCÍA, 2010).

O faturamento e a atração de novos torcedores são desejáveis aos clubes e certamente estão relacionados ao desempenho esportivo apresentado pelas agremiações de futebol profissional em sua história. Dantas e Boente (2011) alertam que quanto maior o recurso gasto, maior é a probabilidade de contratação de grandes jogadores, mas ressalvam que o mercado e o resultado futebolístico não se comportam de forma linear e previsível, pois, entre outros fatores, existe um risco considerável relacionado ao ativo seres humanos, que, ao contrário de máquinas, não presume exatidão de produtividade.

Nesse sentido, a relação entre desempenho financeiro e performance esportiva tem sido estudada na literatura nacional e internacional sem consenso. Trabalhos como os de Pereira; Rezende; Corrar; Lima (2004) e Ferreira; Marques; Macedo (2018) têm sugerido associação entre índices financeiros e desempenho esportivo, enquanto que trabalhos como os de Göllü (2012), Dantas; Macedo; Machado (2016) e Santos, Dani e Hein (2016) apresentam resultados contrários aos primeiros.

Este trabalho propõe o estudo de correlação entre as variáveis independentes: Receita Bruta; Despesa com Salário; Ebit; Endividamento; e a variável dependente: ranking CBF, ao testar duas hipóteses; a H0: Não existe correlação estatística significante entre indicadores financeiros e desempenhos esportivos dos principais clubes de futebol paulistas; e, a H1: Existe correlação estatística significante entre indicadores financeiros e desempenhos esportivos dos principais clubes de futebol paulistas, por meio da ferramenta estatística 'Correlação de 
Spearman'. Os índices de desempenho escolhidos para o estudo estão em consonância com a literatura de base sobre o tema, como os trabalhos de Dimitropoulos (2010), Göllü (2012) e Santos, Dani e Hein (2016).

Para efeitos desta pesquisa foram considerados como principais clubes do estado de São Paulo, os tradicionais: Sport Club Corinthians Paulista, Sociedade esportiva Palmeiras, Santos Futebol Clube e São Paulo Futebol Clube.

A escolha se deveu ao fato de, no período estudado (2011 a 2018), os aludidos clubes sempre disputarem campeonatos competitivos, chegando à conquista de títulos expressivos, por apresentarem grande concentração de torcida, além de estarem sempre revelando grandes jogadores para o exterior.

A pesquisa se justifica pelo fato de a combinação de desempenho esportivo com desempenho econômico-financeiro, ainda ser um assunto relativamente novo no âmbito acadêmico, apresentando pouco volume de publicações nacionais. A grande maioria dos estudos realizados sobre este assunto é relacionada às equipes europeias (CAJAIBA; PEREIRA, 2018).

Outros artigos brasileiros sobre a temática focaram seus estudos em maiores quantidades amostrais, oferecendo uma visão de âmbito nacional. Diferentemente, o presente trabalho buscou regionalizar a análise, focando em um estado da federação e de quatro grandes clubes, conforme apontado por Göllü (2012), ao pesquisar a realidade turca. A inciativa é testar se os resultados isolados dos times da presente amostra, continuariam em consonância aos resultados de Santos, Dani e Hein (2016), por exemplo, que estudaram 36 times de todas as regiões do Brasil, mas sem individualizar os achados.

Assim, os esforços aqui apurados estão alinhados à resposta da questão: Quais indicadores econômico-financeiros guardam relação com a performance esportiva dos principais clubes de futebol do estado de São Paulo? Para auxílio à reposta, pautou-se o seguinte objetivo: analisar se indicadores econômico-financeiros dos principais clubes de futebol do estado de São Paulo estão atrelados aos resultados esportivos conquistados por essas agremiações.

\section{Referencial Teórico}

\subsection{O mercado do futebol no Brasil e no mundo}

O futebol é um dos esportes que mais atrai atletas profissionais, amadores e espectadores. Segundo Dino (2018), estima-se que no Brasil pouco mais de 30 milhões de pessoas pratiquem futebol, sendo, 265 milhões no mundo. De acordo o site oficial da CBF, profissionalmente, são 22.177 atletas no Brasil, vinculados a 742 clubes; na série A do campeonato nacional são 691 atletas, em 20 agremiações. Segundo Parente (2019) “a audiência média é de 7 milhões de 
pessoas, de acordo dados da transmissão ao vivo dos jogos na Globo na grande São Paulo”; que, conforme Sacchitiello (2018), tem uma movimentação estimada de R \$ 1,8 bilhões em patrocínios e demais rendimentos, gerando empregos diretos e indiretos.

Para serem competitivos, os clubes investem muitos recursos financeiros na contratação de jogadores de alto nível. Na última janela europeia do ano 2019, o valor investido por clubes foi aproximadamente de $\mathrm{R} \$ 16$ bilhões de reais, aplicados na venda e compra de jogadores. O Real Madrid, da Espanha, foi o clube que mais investiu. Chegando ao valor de $€ 303$ milhões de euros, seguido de perto por Atlético de Madrid, da Espanha e Borussia Dortmund, da Alemanha, €196 milhões e €127,5 milhões, respectivamente. (REIS, 2019).

Segundo Jakar e Gerretsen (2020), os clubes mais ricos, independentemente do seu modelo de propriedade, são mais propensos a ter mais sucesso e aumentar a lacuna para os mais pobres no rendimento em campo. $\mathrm{Na}$ Europa, a estrutura de propriedade privada é estatisticamente significativa e positivamente associada à probabilidade de se classificar para as últimas rodadas da Liga dos Campeões e, consequentemente, ao aumento de suas receitas.

Entretanto, na visão de Hoffmann, Ging e Ramasamy (2002), o desempenho esportivo do futebol europeu possui muitas outras variáveis, além do orçamento. Os autores apresentam que fatores econômicos, demográficos, culturais e climáticos são importantes. Em particular, temperatura e riqueza per capita, origem latina dos jogadores e tamanho da população também seriam condições associadas ao bom rendimento esportivo.

\subsection{Gestão das agremiações esportivas de futebol profissional no Brasil}

Clubes de futebol na sua maioria são associações sem fins lucrativos. Assim, os recursos devem ser geridos para trazer benefício à sociedade e desenvolver a entidade. Segundo Soriano (2010), a transformação econômico-financeira dos clubes de futebol somente é possível por intermédio do planejamento estratégico, trabalho em equipe, um olhar em longo prazo, liderança hábil e gerenciamento eficaz. No contexto atual, em especial, os clubes estão sendo forçados a trabalhar neste sentido.

Com a extinção do passe em 1998, os clubes de futebol brasileiros, com a aprovação da Lei no 9.615, a chamada "Lei Pelé", tiveram que buscar novas alternativas de receitas. Ou seja, os times, que até então tinham como sua principal fonte de receita a venda do passe de jogadores, foram induzidos a desenvolver novas fontes de recursos. Surgiu uma necessidade de se explorar o produto 'futebol' como um todo, para garantir a própria sobrevivência econômica. De acordo Raja e Morrow (2007), a presença dos objetivos financeiros levanta a questão de como medir o desempenho dos clubes. 
Muito embora os clubes estejam preocupados em disputa de títulos e normalmente não possuírem finalidade lucrativa, o lado econômico financeiro não pode ser esquecido, os custos, despesas, receitas devem ser controladas. O relatório Itaú BBA $(2018$, p. 41) afirma que as dívidas em clubes de futebol: "não chegam a ser um problema incontornável, mas precisam ser tratadas com mais atenção". O mesmo relatório alerta que as dívidas bancárias são aceitáveis para alguns, mas elevadas para a maioria e que os impostos estão alongados, mas como o volume é grande, é preciso preservar o fluxo de caixa para pagá-los.

É latente a preocupação com a parte econômico-financeira das entidades esportivas de futebol, que movimenta bilhões e gera milhares de postos de emprego, além de ser uma grande fonte e entretenimento mundial. Nesse sentido, muito se fala na mudança do modelo de gestão estabelecido pelos clubes. O modelo predominantemente utilizado no futebol brasileiro, com entidades associativas, é atrasado, evidência que não significa que somente o modelo clubeempresa seja válido. (AGÊENCIA BRASIL, 2019).

Experiências brasileiras recentes, com clubes empresa de finalidade lucrativa, têm rendido bons frutos. É o caso de Red Bull Brasil e do Cuiabá, que são agremiações de propriedade particular a disputar o campeonato nacional da primeira divisão. Entretanto, nenhum grande clube tradicional atualmente tem estrutura organizacional de inciativa privada. O Botafogo de Futebol e Regatas, do Rio de Janeiro, flerta com a ideia, mas aguarda sanção presidencial de projeto de lei, para oferecer maior segurança jurídica a investidores.

\subsection{Resultados econômicos e desempenho esportivo: trabalhos anteriores}

Não se deve esquecer que os clubes disputam títulos e, assim sendo, a gestão estratégica da agremiação procura administrar de forma eficaz os recursos, para obter a maximização das receitas, o controle de custos e, simultaneamente, a obtenção de campeonatos (PEREIRA, REZENDE, CORRAR, LIMA, 2004).

Segundo Dantas e Boente (2012), maiores investimentos na contratação de jogadores representam maior potencial de arrecadar receitas e ganhar taças importantes. Todavia, o mercado do futebol apresenta riscos diferentes de outros setores, pois envolve capital humano nos principais processos operacionais relativos ao jogo, notadamente os atletas. Assim, altos investimentos não garantem benefícios econômicos futuros ou títulos.

Nesse sentido, Szymanski e Weimar (2019) demonstraram que choques aleatórios, atribuíveis a desvios do desempenho real de uma equipe em relação ao desempenho esperado para o investimento realizado, são cruciais causas na construção do risco de insolvência de clubes 
alemães. Esses choques frequentemente resultam em rebaixamento para um nível inferior de competição, o que gera menor comparecimento às partidas e receitas.

Dimitropoulos (2010) alerta que os clubes de futebol gregos estariam altamente endividados, com intensos problemas de liquidez e rentabilidade e enfrentando um perigo crescente de dificuldades financeiras ainda maiores, apesar do aumento dos montantes que os clubes de futebol investem. Essa crise pode ser atribuída à má gestão financeira, agregada às ineficiências políticas suportadas durante anos.

A realidade não é diferente no Brasil, conforme Campestrini (2012), que relata que a gestão ou a má aplicação dos princípios de administração no esporte brasileiro no seu sentido estrito dificulta a correlação entre desempenho financeiro e desempenho esportivo, diferente dos grandes clubes da Europa, que lideram tanto a tabela dos campeonatos, quanto a dos indicadores financeiros. Com investimento na gestão de qualidade e competitiva, é possível se tornar um grande clube, a partir de uma equipe competitiva de pequeno e de pequeno-médio porte, com engajamento nas competições que disputa.

No ciclo de palestra da Brasil Futebol Expo em São Paulo, o tema gestão do futebol no Brasil abordou diversos questionamentos acerca da evolução dos clubes brasileiros e afirmou que o problema dos clubes não é dinheiro. Hoje, os clubes da Série A faturam mais de R $\$ 5$ bilhões por ano. O problema é gestão, cravou o sócio da EY para esportes, Alexandre Rangel. (SITE UOL).

Segundo Lopes (2019), os clubes do futebol no Brasil tiveram todas as oportunidades para viverem um bom momento financeiro, mas péssimas administrações ao longo dos anos não apresentaram evolução na criação de valor aos olhos do consumidor e as dívidas só cresceram. Essas entidades apresentaram historicamente evolução constante nas receitas; mesmo em período de estagnação econômica, valorização da televisão, aumento de venda de jogadores e "matchday" em alta, ainda assim, seus gestores não souberam o que fazer com tanto potencial econômico.

Como visto, o futebol movimenta muito dinheiro, mas a ineficiência no processo de gestão dificulta a vida dos clubes financeiramente e esportivamente, ratificando a importância do equilíbrio entre gestão e desempenho esportivo. Essa dicotomia é discutida em pesquisas como a de Gaspareto (2012), que em seu estudo sobre a relação custo operacional e desempenho esportivo, analisando o campeonato brasileiro de futebol, mediante utilização do teste de correlação de Spearman, afirmou haver correlação significativa entre o custo operacional e a pontuação obtida em todas as temporadas pesquisadas, indicando que há maiores chances de sucesso no Campeonato Brasileiro de futebol para as equipes que apresentam maiores investimentos. 
Diferentemente, segundo Göllü (2012), pode-se dizer que não há relação significativa entre indicadores financeiros e classificação no campeonato nacional turco. Santos, Dani e Hein (2016) corroboram esse resultado, afirmando que inexiste correlação estatisticamente significante entre a gestão administrativa e a performance esportiva.

\section{Metodologia}

\subsection{Tipologia}

A tipologia desta pesquisa quanto aos objetivos, é descritiva. Conforme escreveu Gil (2008), a pesquisa descritiva tem como finalidade fundamental a descrição das propriedades e características de determinada população ou fenômeno e a determinação de relações entre diversas variáveis, associadas ao grupo de objetos estudados.

Quanto à abordagem, o estudo é quantitativo, pelo emprego de correlação não paramétrica. Segundo Castilho, Borges e Tanús (2014), esse tipo de abordagem representa tudo aquilo que pode ser mensurado em valores numéricos. Significa quantificar dados, processar informações, assim como empregar recursos e técnicas estatísticas. Tal abordagem pode ser utilizada no desenvolvimento das pesquisas de âmbito das ciências sociais aplicadas, representando, em linhas gerais, uma forma de aumentar a confiabilidade dos resultados.

\subsection{População e amostragem}

A amostragem está constituída por quatro clubes do futebol brasileiro - Santos Futebol Clube, São Paulo Futebol Clube, Sociedade Esportiva Palmeiras e Sport Clube Corinthians Paulista - que são associações com atividade primária de clubes sociais, esportivos e similares, com sedes no estado de São Paulo.

A escolha dos quatro principais clubes do estado de São Paulo se deu pelo fato de que nos oito anos da série temporal estudada, os times sempre disputaram títulos expressivos até as fases finais, além de revelarem grandes jogadores da história do esporte no Brasil e no mundo. A pesquisa se justifica pelo fato de a combinação de desempenho esportivo com desempenho econômico-financeiro ainda ser um assunto relativamente novo no âmbito acadêmico. Conforme Cajaiba e Pereira (2018), a quantidade de produção científica sobre este tema pode ser considerada pequena. Além do mais, a grande maioria dos estudos realizados sobre este assunto é relacionada às equipes europeias. 
O Santos Futebol Clube é um clube de futebol brasileiro que atua especificamente nesta modalidade desportiva. Foi fundado por iniciativa de três esportistas da cidade de Santos: Francisco Raymundo Marques, Mário Ferraz de Campos e Argemiro de Souza Júnior. Hoje, o Santos Futebol Clube é considerado como o legítimo Octacampeão Brasileiro por suas conquistas nacionais nos anos de 1961 a 1965, 1968, 2002 e 2004. Nos campeonatos estaduais foram 22 conquistas, na Taça Libertadores da América foram 03 conquistas e nos Mundiais Interclubes foram duas conquistas (SITE OFICIAL).

Segundo o site oficial do São Paulo Futebol Clube, a grande saga do Tricolor começou quando o futebol dava os primeiros passos no Brasil, com a fundação do clube mais vitorioso da era amadora do esporte: o Club Athlético Paulistano. A trajetória do São Paulo mostra como e por que o clube é um dos mais vitoriosos do futebol brasileiro, com a maior quantidade de conquistas nos três principais torneios de futebol disputados por clubes brasileiros, o Campeonato Brasileiro com seis títulos, a Copa Libertadores da América e o Mundial de Clubes, com três títulos em cada competição.

A Sociedade Esportiva Palmeiras é um clube do futebol brasileiro, fundado em 1914, e como Palestra Itália, levantou sua primeira taça já em 1920. Treze anos depois, com o Torneio Rio-São Paulo de 1933, tornou-se o primeiro campeão interestadual do Brasil e, de quebra, o primeiro campeão da era profissional do futebol brasileiro. Ao longo dos anos, o Palmeiras conquistou diversos títulos na esfera estadual, nacional e internacional (SITE OFICIAL).

O Sport Clube Corinthians Paulista é também um clube do futebol brasileiro. No dia $1^{\circ}$ de setembro de 1910, José Paulino e Cônego Martins, no bairro do Bom Retiro, em conjunto com o grupo de operários formado por Anselmo Corrêa, Antônio Pereira, Carlos Silva, Joaquim Ambrósio e Raphael Perrone fundaram o Sport Club Corinthians Paulista. Com mais oito rapazes, foi desenvolvida a reunião dos pioneiros e sócios fundadores do Timão, tendo o nome inspirado na equipe inglesa Corinthians-Casuals Football Club, que fazia excursão pelo Brasil. A primeira conquista do clube foi em 1914 levantando a taça de campeão paulista; com o passar dos anos, muitas conquistas foram alcançadas no âmbito estadual, nacional e internacional (SITE OFICIAL).

\subsection{Procedimentos de coleta e análise de dados}

Com intuito de cumprimento do objetivo e resposta ao problema propostos, testaram-se as hipóteses: H0: Não existe correlação estatística significante entre indicadores financeiros e desempenhos esportivos dos principais clubes de futebol paulistas; e, H1: Existe correlação 
estatística significante entre indicadores financeiros e desempenhos esportivos dos principais clubes de futebol paulistas.

As medidas financeiras escolhidas como variáveis explicativas foram: a) receita bruta (receita de todas as modalidades esportivas); b) despesa com salário (inclusão dos direitos de imagem); c) Earnings Before Interest and Taxes - Ebit (lucro antes dos juros, impostos, amortizações, depreciações); e d) endividamento (neste caso foi considerado para análise o passivo circulante e não circulante). A medida de desempenho foi o ranking anual divulgado pela Confederação Brasileira de Futebol - CBF para cada time (variável a ser explicada). Tais marcadores foram escolhidos conforme a literatura de base, como os trabalhos de Dimitropoulos (2010), Göllü (2012) e Santos, Dani e Hein (2016).

Os valores foram coletados dos Demonstrativos do Resultado do Exercício - DRE e Balanços Patrimoniais dos clubes. As Demonstrações contábeis utilizadas foram coletadas diretamente dos sites das entidades e da Federação Paulista de Futebol. O período de estudo compreendeu os anos 2011, 2012, 2013, 2014, 2015, 2016, 2017 e 2018, proporcionando 8 observações a cada time.

Conforme fez Göllü (2012), ao estudar clubes turcos, a ferramenta estatística utilizada para análise dos dados foi o método não paramétrico Correlação de Spearman, que é uma medida para correlação de postos (dependência estatística entre a classificação de duas variáveis). O coeficiente avalia com que intensidade a relação entre duas variáveis pode ser descrita pelo uso de uma função monótona. Os índices variam entre -1 e 1, sendo, -1 correlação negativa perfeita, e 1 correlação positiva perfeita.

Após realização dos cálculos, empregando o aplicativo estatístico SPSS, foram elaboradas tabelas para apresentação resumida e padronizada dos resultados que possibilitassem a análise dos níveis de correlação de cada indicador financeiro e a pontuação alcançada no ranking da CBF pelos clubes nos períodos. 


\section{Análise dos Resultados}

\subsection{Santos Futebol Clube}

Tabela 1 - Resultados da Correlação de Spearman para o Santos Futebol Clube

\begin{tabular}{clccccc}
\hline Rô de Spearman & $\begin{array}{c}\text { Receita } \\
\text { Operacional } \\
\text { Bruta }\end{array}$ & $\begin{array}{c}\text { Despesa } \\
\text { com Salários }\end{array}$ & EBIT & Endividamento & $\begin{array}{c}\text { Ranking } \\
\text { CBF }\end{array}$ \\
\hline Receita & Coeficiente de Correlação & 1,000 & 0,643 & $-0,333$ & 0,048 & 0,619 \\
Operacional & Sig. (2 extremidades) & & 0,086 & 0,420 & 0,911 & 0,102 \\
Bruta & $N$ & 8 & 8 & 8 & 8 & 8 \\
Despesa com & Coeficiente de Correlação & 0,643 & 1,000 & $-0,167$ & 0,357 & 0,571 \\
Salários & Sig. (2 extremidades) & 0,086 & & 0,693 & 0,385 & 0,139 \\
& $N$ & 8 & 8 & 8 & 8 & 8 \\
& Coeficiente de Correlação & $-0,333$ & $-0,167$ & 1,000 & 0,286 & $-0,048$ \\
EBIT & Sig. (2 extremidades) & 0,420 & 0,693 & & 0,493 & 0,911 \\
& $N$ & 8 & 8 & 8 & 8 & 8 \\
& Coeficiente de Correlação & 0,048 & 0,357 & 0,286 & 1,000 & 0,667 \\
Endividamento & Sig. (2 extremidades) & 0,911 & 0,385 & 0,493 & & 0,071 \\
& $N$ & 8 & 8 & 8 & 8 & 8 \\
& Coeficiente de Correlação & 0,619 & 0,571 & $-0,048$ & 0,667 & 1,000 \\
Ranking CBF & Sig. (2 extremidades) & 0,102 & 0,139 & 0,911 & 0,071 & \\
& $N$ & 8 & 8 & 8 & 8 & 8 \\
\hline
\end{tabular}

Fonte: Elaborado pelos autores com base nos dados da pesquisa (2020).

Os resultados indicam que não há correlação estatisticamente significante entre os indicadores financeiros e o desempenho esportivo do clube. Mesmo percebendo-se coeficientes de correlação positivos entre as variáveis: Ranking da CBF e Receitas; Ranking da CBF e Despesas com salários; Ranking da CBF e Endividamento; e entre Ranking da CBF e EBIT, quando testados ao nível de significância de 5\% ou menor, não se pôde afirmar que as correlações percebidas teriam significância estatística. Os achados confirmam o que foi apresentado por Göllü (2012) e Santos, Dani e Hein (2016), de que os desempenhos financeiro e esportivo não estariam seguramente correlacionados estatisticamente. 


\subsection{São Paulo Futebol Clube}

Tabela 2 - Resultados da Correlação de Spearman para o São Paulo Futebol Clube

\begin{tabular}{|c|c|c|c|c|c|c|}
\hline \multicolumn{2}{|c|}{ Rô de Spearman } & \multirow{2}{*}{$\begin{array}{c}\begin{array}{c}\text { Receita } \\
\text { Operacional } \\
\text { Bruta }\end{array} \\
1,000\end{array}$} & \multirow{2}{*}{$\begin{array}{c}\begin{array}{c}\text { Despesa } \\
\text { com Salários }\end{array} \\
, 857^{* *}\end{array}$} & \multirow{2}{*}{$\frac{\text { EBIT }}{, 810^{*}}$} & \multirow{2}{*}{$\begin{array}{c}\text { Endividamento } \\
0,595\end{array}$} & \multirow{2}{*}{$\begin{array}{c}\begin{array}{c}\text { Ranking } \\
\text { CBF }\end{array} \\
0,190\end{array}$} \\
\hline Receita & Coeficiente de Correlação & & & & & \\
\hline Operacional & Sig. (2 extremidades) & & 0,007 & 0,015 & 0,120 & 0,651 \\
\hline Bruta & $\mathrm{N}$ & 8 & 8 & 8 & 8 & 8 \\
\hline \multirow{3}{*}{$\begin{array}{c}\text { Despesa com } \\
\text { Salários }\end{array}$} & Coeficiente de Correlação & $857^{* *}$ & 1,000 & 0,595 & 0,571 & 0,333 \\
\hline & Sig. (2 extremidades) & 0,007 & & 0,120 & 0,139 & 0,420 \\
\hline & $\mathrm{N}$ & 8 & 8 & 8 & 8 & 8 \\
\hline \multirow{3}{*}{ EBП } & Coeficiente de Correlação &, $810^{*}$ & 0,595 & 1,000 & 0,190 & 0,071 \\
\hline & Sig. (2 extremidades) & 0,015 & 0,120 & & 0,651 & 0,867 \\
\hline & $\mathrm{N}$ & 8 & 8 & 8 & 8 & 8 \\
\hline \multirow{3}{*}{ Endividamento } & Coeficiente de Correlação & 0,595 & 0,571 & 0,190 & 1,000 & 0,190 \\
\hline & Sig. (2 extremidades) & 0,120 & 0,139 & 0,651 & & 0,651 \\
\hline & $\mathrm{N}$ & 8 & 8 & 8 & 8 & 8 \\
\hline \multirow{3}{*}{ Ranking CBF } & Coeficiente de Correlação & 0,190 & 0,333 & 0,071 & 0,190 & 1,000 \\
\hline & Sig. (2 extremidades) & 0,651 & 0,420 & 0,867 & 0,651 & \\
\hline & $\mathrm{N}$ & 8 & 8 & 8 & 8 & 8 \\
\hline
\end{tabular}

Fonte: Elaborado pelos autores com base nos dados da pesquisa (2020).

Os resultados indicam inexistência de correlação estatisticamente significante entre os indicadores financeiros e o desempenho esportivo do clube. Novamente, foram percebidos valores de coeficiente de correlação positivos entre as variáveis: Ranking da CBF e Receitas; Ranking da CBF e Despesas com salários; Ranking da CBF e EBIT; e Ranking da CBF e Endividamento. Entretanto, quando testados ao nível de significância de 5\% ou menor, não se pôde afirmar que as correlações tivessem significância estatística.

Estes achados corroboram os encontrados por Göllü (2012) e Santos, Dani e Hein (2016), de que não há correlação estatisticamente significativa entre indicadores financeiros e o desempenho das equipes em campo. E contradiz os achados por Pereira; Rezende; Corrar; Lima (2004), que encontraram um grau de correlação que “comprova a hipótese de que desempenho financeiro é compatível com a performance esportiva”. Ressalta-se que as relações entre Receitas e Despesa com Salários; Receitas e EBIT; Receitas e Endividamento, apesar de significativas estatisticamente, nada explicam sobre a variável Ranking CBF, ou seja, não trazem informação relevante sobre a correlação entre os indicadores financeiros e o desempenho esportivo. 


\subsection{Sociedade Esportiva Palmeiras}

Tabela 3 - Resultados da Correlação de Spearman para a Sociedade Esportiva Palmeiras

\begin{tabular}{clccccc}
\hline Rô de Spearman & $\begin{array}{c}\text { Receita } \\
\text { Operacional } \\
\text { Bruta }\end{array}$ & $\begin{array}{c}\text { Despesa com } \\
\text { Salários }\end{array}$ & EBIT & Endividamento & $\begin{array}{c}\text { Ranking } \\
\text { CBF }\end{array}$ \\
\hline Receita & Coeficiente de Correlação & 1,000 &, 976 & 0,667 & 0,119 &, $738^{*}$ \\
Operacional & Sig. (2 extremidades) & & 0,000 & 0,071 & 0,779 & 0,037 \\
Bruta & $N$ & 8 & 8 & 8 & 8 & 8 \\
Despesa com & Coeficiente de Correlação &, 976 & 1,000 & 0,619 & 0,214 & 0,619 \\
Salários & Sig. (2 extremidades) & 0,000 & & 0,102 & 0,610 & 0,102 \\
& $N$ & 8 & 8 & 8 & 8 & 8 \\
& Coeficiente de Correlação & 0,667 & 0,619 & 1,000 & $-0,071$ & 0,381 \\
EBIT & Sig. (2 extremidades) & 0,071 & 0,102 & & 0,867 & 0,352 \\
& $N$ & 8 & 8 & 8 & 8 & 8 \\
& Coeficiente de Correlação & 0,119 & 0,214 & $-0,071$ & 1,000 & 0,048 \\
Endividamento & Sig. (2 extremidades) & 0,779 & 0,610 & 0,867 & & 0,911 \\
& $N$ & 8 & 8 & 8 & 8 & 8 \\
& Coeficiente de Correlação &, $738^{*}$ & 0,619 & 0,381 & 0,048 & 1,000 \\
Ranking CBF & Sig. (2 extremidades) & 0,037 & 0,102 & 0,352 & 0,911 & \\
& $N$ & 8 & 8 & 8 & 8 & 8 \\
\hline **. A correlação é significativa no nível 0,01 (2 extremidades). & & & & \\
*. A correlaç̃o é significativa no nível 0,05 (2 extremidades). & & & & \\
\hline
\end{tabular}

Fonte: Elaborado pelos autores com base nos dados da pesquisa (2020).

O Palmeiras apresentou forte correlação estatisticamente significativa entre Receita Bruta e Ranking CBF, com coeficiente 0,738 , ao nível de significância de 5\%. Os resultados para todas as demais variáveis indicam que não houve correlação significante entre os indicadores financeiros e o desempenho esportivo do clube. Embora se percebam valores de coeficiente de correlação fracos entre as variáveis: Ranking da CBF e Despesas com salários; Ranking da CBF e Endividamento; e forte entre Ranking da CBF e EBIT, quando testados ao nível de significância de $5 \%$, ou menor, não se pôde afirmar que tivessem significativa relação estatística. Apenas o resultado em relação à Receita Bruta se assemelhou ao encontrado por Pereira; Rezende; Corrar; Lima (2004, p. 13): "há um grau de correlação significativo entre receitas e o desempenho em campo". 


\subsection{Sport Clube Corinthians Paulista}

Tabela 4 - Resultados da Correlação de Spearman para o Sport Clube Corinthians Paulista

\begin{tabular}{|c|c|c|c|c|c|c|}
\hline \multicolumn{2}{|c|}{ Rô de Spearman } & \multirow{2}{*}{$\begin{array}{c}\begin{array}{c}\text { Receita } \\
\text { Operacional } \\
\text { Bruta }\end{array} \\
1,000\end{array}$} & \multirow{2}{*}{$\begin{array}{c}\begin{array}{c}\text { Despesa com } \\
\text { Salários }\end{array} \\
, 976^{* *}\end{array}$} & \multirow{2}{*}{$\begin{array}{c}\text { EBIT } \\
0,667\end{array}$} & \multirow{2}{*}{$\begin{array}{c}\text { Endividamento } \\
0,119\end{array}$} & \multirow{2}{*}{$\frac{\begin{array}{c}\text { Ranking } \\
\text { CBF }\end{array}}{, 738^{*}}$} \\
\hline Receita & Coeficiente de Correlação & & & & & \\
\hline Operacional & Sig. (2 extremidades) & & 0,000 & 0,071 & 0,779 & 0,037 \\
\hline Bruta & $\mathrm{N}$ & 8 & 8 & 8 & 8 & 8 \\
\hline \multirow{4}{*}{$\begin{array}{c}\text { Despesa com } \\
\text { Salários }\end{array}$} & Coeficiente de Correlação &, $976^{* *}$ & 1,000 & 0,619 & 0,214 & 0,619 \\
\hline & Sig. (2 extremidades) & 0,000 & & 0,102 & 0,610 & 0,102 \\
\hline & $\mathrm{N}$ & 8 & 8 & 8 & 8 & 8 \\
\hline & Coeficiente de Correlação & 0,667 & 0,619 & 1,000 & $-0,071$ & 0,381 \\
\hline \multirow[t]{2}{*}{ EBIT } & Sig. (2 extremidades) & 0,071 & 0,102 & & 0,867 & 0,352 \\
\hline & $\mathrm{N}$ & 8 & 8 & 8 & 8 & 8 \\
\hline \multirow[t]{3}{*}{ Endividamento } & Coeficiente de Correlação & 0,119 & 0,214 & $-0,071$ & 1,000 & 0,048 \\
\hline & Sig. (2 extremidades) & 0,779 & 0,610 & 0,867 & & 0,911 \\
\hline & $\mathrm{N}$ & 8 & 8 & 8 & 8 & 8 \\
\hline \multirow[t]{3}{*}{ Ranking CBF } & Coeficiente de Correlação &, $738^{*}$ & 0,619 & 0,381 & 0,048 & 1,000 \\
\hline & Sig. (2 extremidades) & 0,037 & 0,102 & 0,352 & 0,911 & \\
\hline & $\mathrm{N}$ & 8 & 8 & 8 & 8 & 8 \\
\hline
\end{tabular}

Fonte: Elaborado pelos autores com base nos dados da pesquisa (2020).

Assim como o Palmeiras, o Sport Clube Corinthians Paulista apresentou forte correlação estatisticamente significativa, apenas, entre Receita Bruta e Ranking CBF. Embora se percebam valores de coeficiente de correlação fracos entre as variáveis: Ranking da CBF e Despesas com salários; Ranking da CBF e EBIT; e entre Ranking da CBF e Endividamento, quando testados ao nível de significância de 5\%, ou menor, não se pôde afirmar que tivessem significativa relação estatística. O resultado, em relação à Receita Bruta, confirmou os achados de Pereira; Rezende; Corrar; Lima (2004). Já para a Despesa com salários, Ebit e Endividamento as correlações foram consideradas não significativas, apresentando-se consonantes às análises de Göllü (2012) e Santos, Dani e Hein (2016).

Ressalta-se que os resultados apresentados pelo Sport Clube Corinthians Paulista e pela Sociedade Esportiva Palmeiras, coincidentemente, mostraram-se estatisticamente idênticos, por conta dos postos explorados na correlação de Spearman apresentarem-se muito parecidos.

\section{Considerações Finais}

Este trabalho procurou analisar se indicadores econômico-financeiros dos principais clubes de futebol do estado de São Paulo estão atrelados aos resultados esportivos conquistados por essas agremiações. 
Entre todos os testes, apenas entre Receita Bruta e Ranking CBF foram percebidas fortes correlações positivas e estatisticamente significantes para Palmeiras e Corinthians, ou seja, especificamente para estes clubes, maiores receitas guardaram correlação com melhores resultados esportivos, da mesma maneira que menores receitas guardaram correlação com piores resultados esportivos. Estes achados estão consonantes aos abordados na literatura por Pereira; Rezende; Corrar; Lima (2004).

Todos os demais resultados não se apresentaram estatisticamente significantes, quando testados ao nível de significância de 5\%, ou menores. Assim, não se pôde afirmar que maiores despesas com salários; melhores marcadores EBIT e maior ou menor endividamento estivessem correlacionados a melhores ou piores performances esportivas dos clubes da amostra. Portanto, os rendimentos dos times nos campeonatos que disputaram não puderam ser explicados pelas variáveis independentes utilizadas neste estudo. Esses resultados refletem o estudo anterior de Göllü (2012), que examinou com metodologia análoga, os principais clubes de futebol da Turquia, bem como os achados de Santos, Dani e Hein (2016).

Desta feita, não foi possível rejeitar a Hipótese H0, ou seja, não existe correlação estatística significante entre indicadores financeiros e desempenhos esportivos dos principais clubes de futebol paulistas, entre 2011 e 2018. Os principais clubes do estado de São Paulo, especificamente, não apresentaram comportamento isolado diverso de estudos anteriores que englobavam amostra nacional, envolvendo clubes de vários estados em um mesmo conjunto de dados.

Embora a pesquisa não tenha encontrado expressiva correlação entre os indicadores estudados, não é possível inferir que os resultados esportivos são aleatórios, quanto ao nível de gestão, ou seja, que clubes organizados e desorganizados, endividados ou não, possuem as mesmas probabilidades de rendimento esportivo.

Os resultados podem servir de base a futuros estudos relacionados à importância da gestão no desempenho esportivo dos clubes de futebol, que ainda são muito escassos em nível nacional. Sugere-se para futuros trabalhos, o uso de ferramentas estatísticas e variáveis que possibilitem a medição de probabilidades da interferência da administração eficiente sobre as performances esportivas. 


\section{REFERÊNCIAS}

BEUREN, I. M. (Org.) Como elaborar trabalhos monográficos em Contabilidade - Teoria e prática. São Paulo: Atlas, 2009.

CHAVES, L. Modelos de clube-empresa têm realidades diferentes no futebol. Agência Brasil. 2019. Disponível em: <http://agenciabrasil.ebc.com.br/esportes/noticia/2019-

09/modelos-de-clube-empresa-tem-realidades-diferentes-no-futebol $>$ Acesso em: 14 de nov. de 2019.

CAJAIBA, K. S.; PEREIRA, E. R. N. Análise bibliométrica da produção científica nacional sobre agremiações esportivas de futebol profissional em periódicos de ciências contábeis entre 2012 e 2016. Ric - revista de informação contábil, v. 12, n. 1, p. 52-76, jan./mar. 2018. Disponível em: <https://periodicos.ufpe.br/revistas/ricontabeis/article/view/235032>. Acesso em: 15 de nov. de 2019.

CAMPESTRINI, G. A (má) gestão equilibra. Universidade do Futebol: transformação pelo conhecimento, 2012. Disponível em: <https://universidadedofutebol.com.br/a-ma-gestaoequilibra/>. Acesso em: 01 de outubro de 2019.

CASTILHO, A. P.; BORGES, N. R. M.; TANÚS, V. P. Manual de Metodologia Científica. $2^{\mathrm{a}}$ ed. Itumbiara: ILES/ULBRA, 2014.

CONFEDERAÇÃO BRASILEIRA DE FUTEBOL - CBF. Raio-X do mercado 2019: números gerais de registro. Disponível em: <https://www.cbf.com.br/acbf/informes/index/raio-x-do-mercado-2019-numeros-gerais-de-registro> Acesso em: 20 de outubro de 2019.

DANTAS, M. G. da S.; BOENTE, D. R. A Utilização da Análise Envoltória de Dados na Medição de Eficiência dos Clubes Brasileiros de Futebol. Revista Contabilidade Vista \& Revista, Universidade Federal de Minas Gerais, Belo Horizonte, v. 23, n. 4, p. 101-130, abr./jun. 2012. Disponível em: <http://www.spell.org.br/documentos/ver/9879/a-utilizacao-da-analiseenvoltoria-de-dados-na-medicao-de-eficiencia-dos-clubes-brasileiros-de-futebol $>$. Acesso em: 31 de out. 2019.

DANTAS, M. G. da S.; BOENTE, D. R. A eficiência financeira e esportiva dos maiores clubes de futebol europeus utilizando de Análise Envoltória de Dados. Revista de Contabilidade e Organizações - RCO, Ribeirão Preto, v. 5, n. 13, p. 75-90, set./dez. 2011. Disponível em: <https://www.revistas.usp.br/rco/article/view/34805/162262>. Acesso em: 28 de out. 2019.

DANTAS, M. G. da S; MACEDO, M. A. da S.; MACHADO, M. A. V. Eficiência dos custos operacionais dos clubes de futebol do Brasil. Revista Contabilidade Vista \& Revista - ISSN 0103-734X, Universidade Federal de Minas Gerais, 23 Belo Horizonte, v. 27, n. 2, mai/ago. 2016. Disponível em:

<https://revistas.face.ufmg.br/index.php/contabilidadevistaerevista/article/view/3322>.

Acesso em 13 de nov. de 2019.

DIMITROPOULOS, P. The Financial Performance of the Greek Football Clubs. Choregia: sport management international journal, v. 6, n. 1, p. 5 - 27, 2010. Disponível em: <https://www.researchgate.net/publication/43920165_The_Financial_Performance_of_Greek_ 
Football_Clubs\#: :text $=$ The $\% 20$ analysis $\% 20$ of $\% 20$ the $\% 20$ clubs,football $\% 20$ clubs $\% 20$ invested $\% 20$ during\%202005. $>$. Acesso em 16 de jun. de 2021.

DINO. Divulgador de Notícias. Quais os esportes mais praticados no Brasil? 2018.

Disponível em: <https://www.dino.com.br/releases/quais-os-esportes-mais-praticados-nobrasil-dino890157268131> Acesso em: 20 de out. de 2019.

ESPITIA, E. M.; GARCÍA, C. L. I. Measurement of the efficiency of football teams in the Champions League. Managerial and Decision Economics, v. 31, p. 373-386, 2010. Disponível em:

<https://www.researchgate.net/publication/46509535_Measurement_of_the_efficiency_of_foo tball_teams_in_the_Champions_League >.Acesso em: 20 de out. de 2020.

ESPN. Brasil tem 23.238 jogadores que ganham até $\mathbf{R} \$ \mathbf{1 . 0 0 0}$, e um que fatura mais de $\mathbf{R} \$$ 500 mil. 2016. Disponível em: <http://www.espn.com.br/noticia/579836_brasil-tem-23238jogadores-que-ganham-ate-r-1000-e-um-que-fatura-mais-de-r-500-mil $>$ Acesso em: 20 de out. de 2019.

ESPN. Flamengo e Palmeiras já têm dinheiro para estar entre $\mathbf{3 0}$ clubes mais ricos do mundo, e top 20 não está longe. 2019. Disponível em:

$<$ http://www.espn.com.br/blogs/paulocobos/764209_flamengo-e-palmeiras-ja-tem-dinheiropara-estar-entre-30-clubes-mais-ricos-do-mundo-e-top-20-nao-esta-longe> Acesso em: 10 de nov. de 2019.

FPF - FEDERAÇÃO PAULISTA DE FUTEBOL. Disponível em: <http://futebolpaulista.com.br/Home/> Acesso em: 21 de setembro de 2019.

FERREIRA, H. L.; MARQUES, J. A. V. da C.; MACEDO, M. A. da S. Desempenho econômico-financeiro e desempenho esportivo: uma análise com clubes de futebol do Brasil. Contextus - revista contemporânea de economia e gestão, v. 16, n. 3, set./dez. 2018. Disponível em: <http://periodicos.ufc.br/contextus/article/view/39907>. Acesso em: 20 de out. de 2019.

GASPARETO, T. M. Relação entre custo operacional e desempenho esportivo: análise do campeonato brasileiro de futebol. Rev Bras Futebol, v.5, n. 2, p. 28 - 40, Jul./Dez. 2012. Disponível em: <https://rbf.ufv.br/index.php/RBFutebol/article/view/106>. Acesso em 31.10.2019.

GIL, A. C. Métodos e Técnicas de Pesquisa Social. 6. Ed. Atlas, 2008.

GÖLLÜ, E. Impact of the financial performances of incorporations of football clubsin the domestic league on their sportive performances: a study covering four major football clubs in Turkey. Pamukkale Journal of Sport Sciences, v .3, n.1, p. 20 - 29, 2012. Disponível em: $<$ https://www.researchgate.net/publication/259115797_IMPACT_OF_THE_FINANCIAL_P ERFORMANCES_OF_INCORPORATIONS_OF_FOOTBALL_CLUBS_IN_THE_DOMES TIC_LEAGUE_ON_THEIR_SPORTIVE_PERFORMANCES_A_STUDY_COVERING_F OUR_MAJOR_FOOTBALL_CLUBS_IN_TURKEY>. Acesso em: 25 de out. 2019.

HOFFMANN, R.; GING, L. C.; RAMASAMY, B. The Socio-Economic Determinants of International Soccer Performance. Journal of Applied Economics. v. 5, n.2, p. 253 - 272, 2002. Disponível em: 
<https://www.tandfonline.com/doi/abs/10.1080/15140326.2002.12040579>. Acesso em 16 de jun. 2021.

JAKAR, G.; GERRETSEN, S. Ownership in European Soccer, Financial Fair Play, and Performance in UEFA's 2006-2018 Champions League Tournaments. Journal of Sport Management, v. 1, n. 3, p. 1 -11.2020. Disponível em:

$<$ https://www.researchgate.net/publication/348391293_Ownership_in_European_Soccer_Fina ncial_Fair_Play_and_Performance_in_UEFA's_2006-2018_Champions_League_Tournaments>. Acesso em: 16 de jun. de 2021.

LOPES, D. Maquina do Esporte. Ernest Young conclui: falta gestão ao futebol brasileiro, e não dinheiro. 2019. Disponível em: < https://maquinadoesporte.uol.com.br/artigo/ eyconclui-falta-gestao-ao-futebol-brasileiro-e-nao-dinheiro_38083.html> Acesso em: 01 de outubro de 2019.

NASCIMENTO, J. C. H. B.; NOSSA, V.; BERNARDES, J. R.; SOUSA, W. D. A eficiência dos maiores clubes de futebol brasileiros: Evidências de uma análise longitudinal no período de 2006 a 2011. Revista Contabilidade Vista \& Revista, Belo Horizonte, v. 26, n. 2, p. 137-161, maio/ago. 2015. Disponível em:

$<$ https://revistas.face.ufmg.br/index.php/contabilidadevistaerevista/article/view/2707\#: :text $=$ Como $\% 20$ principal $\% 20$ resultado $\% 2 \mathrm{C} \% 20$ notou $\% 2$ Dse, $\mathrm{em} \% 20$ todas $\% 20$ as $\% 20$ abordagens $\% 2$ Outilizadas. >. Acesso em: 31 de out. de 2019.

O DIA. Flamengo investe pesado em contratações e supera gastos de grandes times da Europa. 2019. Disponível em: <https://odia.ig.com.br/esporte/2019/07/5663356-flamengo-investe-pesadoem-contratacoes-e-supera-gastos-de-grandes-times-da-europa.html> Acesso em: 10 de novembro de 2019.

PARENTE, E. Brasileirão 2019 cresce em audiência e nas redes sociais. 2019. Disponível em: < https://telaviva.com.br/18/10/2019/brasileirao-2019-cresce-em-audiencia-e-nas-redessociais/> Acesso em: 17 de novembro de 2019.

PEREIRA, C. A.; REZENDE, A. J.; CORRAR, L. J.; LIMA, E. M. A gestão estratégica de clubes de futebol: uma análise da correlação entre performance esportiva e resultado operacional. In: IV CONGRESSO USP DE CONTROLADORIA E CONTABILIDADE. Anais... São Paulo: USP, 2004. Disponível em:

<https://congressousp.fipecafi.org/anais/artigos42004/336.pdf>. Acesso em: 31.10.2019.

QUESTION PRO. Saiba do que se trata coeficiente de correlação de Spearman. Disponível em: <https://www.questionpro.com/blog/pt-br/coeficiente-de-correlacao-de-spearman/> Acesso em: 01 de outubro de 2019.

RAJA, I. G.; MORROW, S. Measuring efficiency and productivity in professional football teams: evidence from the English Premier League. Central European Journal of Operations Research, v. 15, n. 4, p. 309 - 328, 2007. Disponível em: $<$ https://www.researchgate.net/publication/46537028_Measuring_efficiency_and_productivity_ in_professional_football_teams_Evidence_from_the_English_Premier_League $>$. Accesso em: 30 de out. 2019.

RELÁTORIO BBA ITAÚ. Análise Econômico-Financeira dos Clubes Brasileiros de Futebol. 2018. Disponível em: 
<https://www.itau.com.br/_arquivosestaticos/itauBBA/Analise_Clubes_Brasileiros_Futebol_It au_BBA.pdf>.Acesso em: 12 de nov. de 2019.

REIS, Rafael. Janela de transferências chega a $\mathbf{R} \$ 16$ bi; veja os 10 reforços mais caros. 2019. Disponível em: < https://blogdorafaelreis.blogosfera.uol.com.br/2019/07/09/janela-detransferencias-chega-a-r-16-bi-veja-os-10-reforcos-mais-caros/> Acesso em: 10 de novembro de 2019.

SACCHITIELLO, B. Cotas de patrocínio do Futebol 2019 da Globo somam R\$ 1,8 bi. Disponível em: < https://www.meioemensagem.com.br/home/midia/2018/09/03/cotas-depatrocinio-do-futebol-2019-da-globo-somam-r-18-bi.html> Acesso em: 20 de outubro de 2019.

SANTOS, C. A., DANI, A. C., HEIN, N. Estudo da relação entre os rankings formados pela confederação brasileira de futebol e a partir de indicadores econômico-financeiros dos clubes de futebol brasileiros. Podium: Sport, Leisure and tourism review, v.5, n.3, Set./Dez., 2016

SANTOS FUTEBOL CLUBE. FUNDAÇÃO. Disponível em: <https://www.santosfc.com.br/clube/> Acesso em: 17 de setembro de 2019.

SÃO PAULO FUTEBOL CLUBE. História do SPFC. Disponível em: <http://www.saopaulofc.net/spfcpedia/conquistas> Acesso em: 17 de setembro de 2019.

SOCIEDADE ESPORTIVA PALMEIRAS. História. Disponível em:

<http://www.palmeiras.com.br/historia/titulos> Acesso em: 21 de setembro de 2019.

SORIANO, F. A bola não entra por acaso. Larousse. $1^{\text {a }}$ ed. 2010.

SPORT CLUBE CORINTHIANS PAULISTA. Clube História. Disponível em: <https://www.corinthians.com.br/clube/historia> Acesso em: 21 de setembro de 2019.

SZYMANSKI, S.; WEIMAR, D. Insolvencies in Professional Football: A German

Sonderweg. International Journal of Sport Finance, v. 14, n. 1, p. 54 - 68, 2019. Disponível em: $<$ https://www.researchgate.net/publication/330802178_Insolvencies_in_Professional_Football _A_German_Sonderweg>.Acesso em: 16 de jun. 2021.

TRANSFERMARKT. Competições: campeonato brasileiro série A. Clubes da Série A 2019. Disponível em: <https://www.transfermarkt.com.br/campeonato-brasileiro-seriea/startseite/wettbewerb/BRA1> Acesso em: 20 de outubro de 2019.

TREASY. O que você precisa saber sobre os principais indicadores financeiros de uma empresa, Siteware. 2018. Disponível em: <https://www.treasy.com.br/blog/indicadoresfinanceiros-de-uma-empresa/> Acesso em: 01 de outubro de 2019.

TRIVIÑOS, A. N. S. Introdução à pesquisa em ciências sociais: a pesquisa qualitativa em educação. São Paulo: Atlas. 1987. 